\title{
A REVIEW ON HYDROXYAPATITE-BASED SCAFFOLDS AS A POTENTIAL BONE GRAFT SUBSTITUTE FOR BONE TISSUE ENGINEERING APPLICATIONS
}

\author{
Krishnamurithy $\mathbf{G}^{1,2}$ \\ Malaya, 50603 Kuala Lumpur

\section{Correspondence:} \\ G. Krishnamurithy \\ Musculoskeletal Science Research Group, \\ Department of Molecular and Clinical Cancer Medicine, \\ Institute of Translational Medicine, \\ Faculty of Health and Life Sciences, \\ University of Liverpool. \\ Liverpool. L69 3GA. \\ Mobile: +447448228020 (UK) \\ +60126725034 (Malaysia) \\ Email: veda_g82@hotmail.com
}

1 Musculoskeletal Science Research Group, Department of Molecular and Clinical Cancer Medicine, Institute of Translational Medicine, Faculty of Health and Life Sciences, University of Liverpool, L69 3GA Liverpool

2 Tissue Engineering Group (TEG), Department of Orthopaedic Surgery, NOCERAL, Faculty of Medicine, University of

\begin{abstract}
The biocompatibility and similarity of hydroxyapatite (HA) to the mineral composition of the bone has made HA a potential candidate in bone tissue engineering (BTE). Over the past few decades, its application as bone graft in combination with stem cells has gained much importance. The use of bone marrow-derived mesenchymal stromal cells (MSCs) will enhance the rate and quality of defect repair. However, application of hydroxyapatite as a material to develop a 3-dimension scaffold or carrier to support MSCs in vitro is still in its infant stage. This review will discuss the source, manufacturing methods and advantages of using HA scaffolds in bone tissue engineering applications.
\end{abstract}

Keywords: hydroxyapatite, mesenchymal stem cell, porosity, sintering

Abbreviations: BDHA, Bovine-derived Porous hydroxyapatite scaffold; BTE, bone tissue engineering; $h B M S C s$. human bone marrow-derived mesenchymal stromal cells; OPCs, osteoprogenitor cells; TCP, Tricalcium phosphate.

\section{Introduction}

The use of three-dimensional (3D) scaffold has been commonly accepted as an essential constituent in bone tissue engineering (1). At such, various types of scaffolds such as natural, synthetic, or a combination of both have been developed, and numerous materials have been introduced as potential materials for developing these scaffolds. Hydroxyapatite (HA), a predominant mineral component found in bones and coral, has been widely used as bone graft since the 1960s and could be a potential candidate for bone tissue engineering (2). Due to its osteoconductivity, biocompatibility and biodegradability, HA has been highly favored in surgical reconstruction of bones (3). In addition, bone implants such as titanium and titanium alloys have been coated with HA to enhance osteointegration with the host tissue (4). Later, studies on the application of HA as a scaffold for cell-based therapy have been carried out. It has been described that for the development of a successful scaffold, a 3D interconnected porous structure is necessary to allow cell attachment, proliferation and differentiation. Whilst this remains true, the use of HA in BTE has not been forthcoming owing to the high cost involved in producing the final product. This review discusses the use of HA scaffold in BTE, including my current research on the development of HA scaffold. Using a novel thermal calcination technique we demonstrated that HA in the form of porous biomaterial can be produced inexpensively with bovine bone that is readily available 
in abundance $(5,6)$. We further tested the efficacy and biocompatibility of this material and we showed significant increased in the proliferation and differentiation of human bone marrow-derived mesenchymal stromal cells (hBMSCs) in a bovine-derived HA (BDHA) (Fig.1) scaffold that was produced using a novel thermal calcination method (6), supporting the fact that BDHA produced using our method improves MSC proliferation.

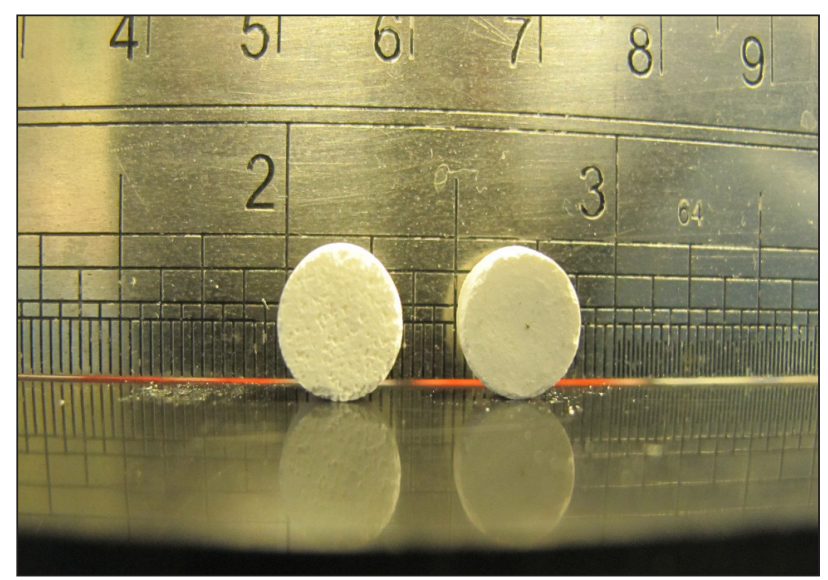

Figure 1: Bovine-derived Porous Hydroxyapatite Scaffold (BDHA)

\section{Problems in treating critical bone defects}

The management of critical-sized bone defects such as those caused by trauma and bone resection pose a substantial clinical challenge in orthopaedic surgery $(7,8)$. Critical bone defects, being referred to a bone discontinuity that will not heal spontaneously and will require secondary intervention (9), occur mainly due to inadequate blood supply. It is possible that during trauma and surgical disruption and also instability at the fracture site, leads to the formation of delayed or non-union bones (10). These critical bone defects, which are subjected to several factors, have increased risk of non-union of the bone. These factors may include poor blood supply, infection and/or extensive soft tissue damage, bone gap or fracture comminution and inadequate fracture fixation (11). Consequently, several treatments have been used for decades to overcome these complications. Internal plate fixation and intramedullary nailing are the recommended surgical treatments for patients with these injuries. Despite sufficient stability offered by the technique, several problems such as vascular damages, soft tissue detachment and periosteal debridement have yet to be resolved $(10,12)$. Hence, external fixators such simple or circular types have been developed based on the principles described by llizarov with the aim to stabilize the affected non-unions. Results of the technique employed have demonstrated good outcomes $(13,14)$. However, distraction osteogenesis and bone transport exhibited some technical hitches, which require proper surgical training and specific set of skills (10). Reliability of internal and external fixation in treating critical bone defects were further enhanced with the use of bone graft materials. The incorporation of autografts in defect sites using internal and external fixation techniques has shown excellent vascularity and bony ingrowth within the host tissue. However, the use of autograft possesses several disadvantages such as limited availability and patient site morbidity. To overcome this issue, allograft was introduced as an alternative to autograft (14).

Tissue engineering was introduced in the early 1990s to address the limitations of tissue grafting. This technique involves the combination of cells, scaffolds and biomolecules to develop functional substitutes (16). Thereafter, various scaffolds based on calcium and phosphate compound were developed as bone-graft substitutes. Moreover, these scaffolds have further evolved by the use of cells with osteogenic potential to enhance the guided-tissue regeneration (17). The use of cells-scaffold constructs incorporation in critical bone defects appears to create similar scenarios to that of natural bone healing process.

\section{Bone grafts as a scaffolding material}

\section{The concept of osteoconduction and osteoinduction in scaffolds}

Scaffolds proposed for BTE should possess osteoconductive and osteoinductive properties. The term osteoconductive is defined as the ability of the bone to grow on the contacted surface. In another scenario where if porous scaffolds are exposed to bone tissue, the scaffolds should be able to permit cell contact and grow into the scaffolds (18). Cornel and colleagues have suggested that when osteoconductive scaffolds are placed in an osseous environment, living tissues from the host bed will migrate into the scaffold and eventually induce new bone formation and incorporation of that structure (19). This leads to a strong fixation of implanted scaffolds with the host osseous surfaces which has been clearly illustrated by Nouri and co-researchers (20). For the past few decades, autograft and allograft have been widely used in critical bone defects due to their excellent osteoconductive properties $(21,22)$. However, owing to the limited supply of autograft and potential disease transmission of allograft, ceramics-based materials have been employed more widely. Hydroxyapatite and tri-calcium ceramic materials are the most widely used ceramic materials in orthopaedic applications. These materials are frequently used as a coating body for metal implants to enhance osteoconduction of the metal surface to the host osseous environment $(23,24)$. On the other hand, ceramics have also been fabricated into porous 3-D scaffolds as gap filler in critical bone defects with the assistance of a fixator. Excellent host bony ingrowth has been noticed in many clinical studies. Over the years, osteoconductive ceramic scaffolds with only structural supporting network evolved into osteoinductive scaffolds which promote desirable biological events between scaffolds, cells and the host tissue. 
Osteoinduction refers to the ability to induce undifferentiated multipotent mesenchymal stromal cells and osteoprogenitor cells (OPCs) to differentiate into bone forming cells by one tissue, or the product from that tissue (25). The role of osteoprogenitor cells in bone healing is apparent. At the time of injury, local multipotent mesenchymal stromal cells and osteoprogenitors cells from periosteum and endosteum stimulate paracrine and autocrine activities. The release of growth factors such as cytokines, BMP-2, TGF- $\beta$, PDGF and many recruits systemic MSCs and OPCs into the injured site. This is also known as cell homing phenomenon where cells are chemotactically attracted to the fracture site (26). These growth factors eventually cause a sequence of events which include cell proliferation and differentiation, working in concert to stimulate new bone formation. This principle has been well described. The incorporation of MSCs or OPSs and osteogenic molecules into scaffolds to improve the scaffolds from osteoconductive into osteoinductive potential has been developed over the years. In an in vitro preliminary study, incorporating MSCs and BMP-7 into porous hydroxyapatite scaffolds have been shown to increase cell proliferation and differentiation over the time as compared to acelullar scaffolds (27). Other studies for example, have demonstrated that human MSCs loaded HA/ TCP biphasic constructs implanted subcutaneously in mice model showed the differentiation of MSCs and increased in osteocalcin expression (28).

\section{Hydroxyapatite-based bone graft substitutes}

\section{Advantages of hydroxyapatite}

Hydroxyapatite (HA) has a molecular formula of $\mathrm{Ca}_{10}$ $\left(\mathrm{PO}_{4}\right)_{6}(\mathrm{OH})_{2}$. It is a member of the calcium phosphate group with 1.67 stoichiometric of $\mathrm{Ca} / \mathrm{P}$ ratio (29). HA has been used widely as a bone graft substitute to treat critical bone defects since many decades ago $(30,31)$. The primary reason for this is because HA mimics the crystalline phase of natural bone. Since 1970s, HA has been used either in blocks or as granules in multidisciplinary field such in orthopaedic and craniofacial surgery (32). During the 1970s, the real role of HA was not clearly understood. The ultimate goal in the 1970s was to just treat bone defects with autograft or allograft substitutes to enhance bone healing. Then, the outstanding outcome of HA in bone healing had encouraged researchers to gain further understanding into the role of the implant-tissue interphase between HA and host bone tissue. Since then, material-tissue interphase was extensively studied. A strong fixation between implant-tissue interphase is the first step to determine the success of an implant into the fracture site. This implant has been shown to possess bioactive surface, thus it can elicit a specific biological response at the interphase of the material, which results in the formation of a bond between the tissue and the material (33). This phenomenon is also known as biological fixation of the material to the host tissue. HA has been proven in many studies that its chemical composition can create an environment compatible for bone ingrowth (34). It also further elaborated as a class B osteoconductive material because it provides biocompatible interphase along which permits bone cells migration (35). Besides, HA is regarded as a biocompatible material because it tends to integrate well into host tissue without eliciting an immune response (36). Another advantage of HA is that it can be used as a raw material in a powder form as bone filler during small fracture or can be fabricated into 3-D scaffolds to treat large bone defects. The excellent biocompatibility of HA would suggest HA as a possible first choice in bone fracture reconstruction (37). However, despite its excellent biocompatibility, HA has inherently poor intrinsic biomechanical properties, weak tensile strength and inherent brittleness. These limit the application of HA as a high load-bearing material which necessitates the need for external or internal fixators when used clinically $(37,38)$. Although the initial toughness of this HA scaffold is an issue, over time, the pure HA scaffold provides an ideal template for bone ingrowth, thus resulting in creeping substitution i.e. replacement of grafted HA scaffold with that of natural tissues. Furthermore, some studies have proven the notion that, the process of bone regeneration is initiated with the secretion of collagen by osteoid at a continuous rate. Over time, this material will compress and eventually improve the toughness of the newly formed bone $(37,39)$.

\section{Manufacturing methods of hydroxyapatite}

Porous HA can be prepared either from natural or synthetic sources. Various fabrication methods are available to produce porous HA (40-42). The coralline-based porous HA can be produced by the aforementioned method. These scaffolds possess a vast range of pore size between 200 to $500 \mu \mathrm{m}$. In another method, starch suspension is mixed with $\mathrm{HA}$ powder and burned at $800^{\circ} \mathrm{C}$ to produce an interconnected porous scaffold. This method is known as starch consolidation where porous HA scaffolds can be produced using natural or synthetic HA. Later, gelcasting polymer sponge method was introduced by Ramay and partners. This method produced a uniform and interconnected HA scaffolds with a pore size between 200 to $400 \mu \mathrm{m}$ (43). Another common method to produce porous HA scaffolds from synthetic HA is the slurry foaming method. This method has been employed to produce a porous scaffold with porosity around 30 to $40 \%$ and pore size between 100 to $500 \mu \mathrm{m}$. In our study, a novel thermal calcination technique was used to produce BDHA scaffold (6) and the preliminary study demonstrated that the material produced using this technique not only possess the desired quality but can be produced at a lower cost, larger quantities and without the use of harmful chemical. Micro-computer tomography images of porous BDHA are shown in figure $2 \mathrm{~A}$ and $\mathrm{B}$. 

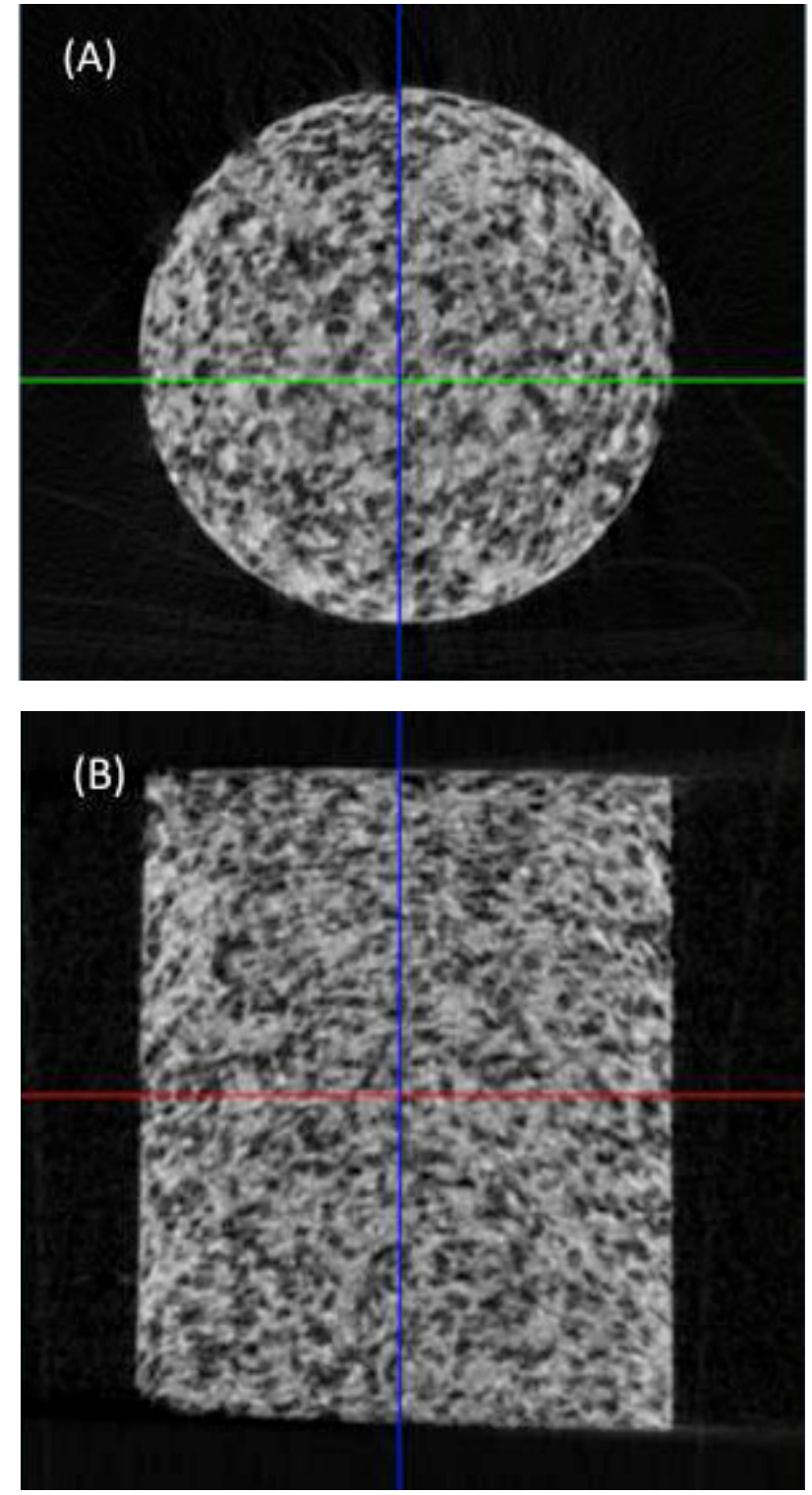

Figure 2: Micro computer tomography of BDHA, (a) Coronal view, (b) Sagittal view.

\section{Sources of hydroxyapatite}

HA can be synthesized from natural or synthetic derivatives. A common natural $\mathrm{HA}$ is derived from marine coral. This coral-based HA has a natural structure to the cancellous bone and the chemical composition of HA of coral is similar to that of natural bone. They can be produced via hydrothermal conversion of calcium carbonate skeleton of coral into calcium phosphate HA (44). Another source of HA is through the direct conversion of human cancellous bone into calcium phosphate HA via hydrothermal process (45). $\mathrm{HA}$ can also be produced from bovine bone by de-fatting continued calcination at $900^{\circ} \mathrm{C}$ using hydrothermal process (5).The synthetic HA can be produced from chemical reaction of calcium and phosphate elements via chemical precipitation method. Calcium nitrate and di-ammoium hydrogen phosphate salts have been precipitated from the aqueous solutions to produce pure synthetic HA powder (46). Another similar precipitation method employed by
Bouyer and partners to produce synthetic HA using calcium hydroxide and orthophosphoric acid (47). Sol-gel method is another way to produce pure synthetic HA using calcium and phosphorus at molecular level (48). The production of porous scaffold using natural and synthetically-derived $\mathrm{HA}$ will be discussed in later sections.

\section{Issues of HA in clinical applications}

There are several issues related to HA in clinical application. In comparison to class $A$ biomaterials such as bioactive glasses and ceramic glasses, the rate of bone bonding with HA after implantation is relatively low (49). Therefore, the recovery time of patients is fairly long. The synthetic HA bone graft substitutes fabricated using chemical process may also elicit immune reaction in the body. Cost of scaffolds manufacturing would be another issue in clinical application. Due to the exorbitant cost involved in the production techniques and expensive raw material, costeffective manufacturing techniques have become a major issue for the use of HA in clinical applications (50).

\section{Advances in hydroxyapatite development to enhance bone healing}

The application of bone graft substitutes in critical bone defects has further evolved in tissue engineering with the advent of using cell, scaffold and various growth molecules (51). HA has always been regarded as an exclusive osteoconductive material (52). With the emergence of cellbased therapy, this has changed the paradigm of HA from being osteoconductive only into osteoinductive material. This has been achieved through the introduction of cells or growth factors into the HA scaffolds. For instance, biological properties of HA can be improved by doping small amount of elements such as growth factors, found in physiological bone (53). These constructs influence dissolution rate of apatite and have induced the proliferation of human osteoblast-like cells in vitro. This process may encourage osteointegration of implant to the osseous environment. Such notion has been proven via many clinical studies where implanted cell-HA construct has improved the bone healing in critical size defects (54). In our in vitro study, we have demonstrated that BDHA which has been loaded with MSCs showed significant increased in cell proliferation as compared to monolayer control (6).

\section{Summary}

This review paper described the potential use of HA underpinned its scaffolding or carrier properties for mesenchymal stromal cell in bone tissue engineering. Various manufacturing methods have been introduced to produce the most functional HA scaffold, yet the one that endows all the ideal quality in human bone reconstruction has not materialized. Therefore, there remain rooms for the development of this material in the advancement of bone tissue engineering. The porous BDHA scaffold 
introduced in the present study provides the fundamental steps to evaluate the biological properties of the scaffold such as cell proliferation and osteogenic potential of future ceramics based scaffolds. However, in vivo study to demonstrate cell proliferation and osteogenic potential of scaffold is highly imperative.

\section{Acknowledgement}

The author is grateful to the HIRG-MOHE University of Malaya.

\section{References}

1. Demirbag B, Huri PY, Kose GT, Buyuksungur A \& Hasirci V. Advanced cell therapies with and without scaffolds. Biotechnol J 2011; 6(12): 1437-1453.

2. Dorozhkin SV. Bioceramics of calcium orthophosphates. Biomaterials 2010; 31(7): 1465-1485.

3. Hallman $M$, Cederlund $A$, Lindskog $S$, Lundgren $S$ \& Sennerby L. A clinical histologic study of bovine hydroxyapatite in combination with autogenous bone and fibrin glue for maxillary sinus floor augmentation. Clin Oral Implants Res 2001; 12(2): 135-143.

4. Søballe K, Hansen, ES, B.-Rasmussen H, Jorgensen $\mathrm{PH} \&$ Bunger $\mathrm{C}$. Tissue ingrowth into titanium and hydroxyapatite-coated implants during stable and unstable mechanical conditions. J of Orthop Res 1992; 10(2): 285-299.

5. Herliansyah MK, Nasution DA, Hamdi M, Wildan MW \& Tontowi AE. Preparation and Characterisation of Natural Hydroxyapatite: A Comparative Study of Bovine Bone Hydroxyapatite and Hydroxyapatite from Calcite. Mater Sci Forum 2007; 561-565: 14411444.

6. Krishnamurithy $G$, Murali MR, Hamdi M, Abbas AA, Raghavendran HB, Kamarul T. Characterization of bovine-derived porous hydroxyapatite scaffold and its potential to support osteogenic differentiation of human bone marrow derived mesenchymal stem cells. Ceram Int 2013; http://dx.doi.org/10.1016/j. ceramint. 2013.06.067.

7. Chatterjea A, Meijer G, van Blitterswijk C \& de Boer J. Clinical Application of Human Mesenchymal Stromal Cells for Bone Tissue Engineering. Stem Cells Int 2010; 2010: 12.

8. Dimitriou R, Jones E, McGonagle D \& Giannoudis PV. Bone regeneration: current concepts and future directions. BMC Med 2011; 9(1): 66.

9. Balogh ZJ, Reumann MK, Gruen RL Mayer-Kuckuk P, Schuetz MA, Harris IA \& et al. Advances and future directions for management of trauma patients with musculoskeletal injuries. Lancet 2012; 380(9847): 1109-1119.

10. Megas P. Classification of non-union. Injury 2005; 36(4, Supplement): S30-S37.

11. Romano CL, Romano D \& Logoluso N. Low-Intensity Pulsed Ultrasound for the Treatment of Bone Delayed
Union or Nonunion: A Review. Ultrasound in Med Biol 2009; 35(4): 529-536.

12. Cove JA, Lhowe DW, Jupiter JB \& Siliski JM. The Management of Femoral Diaphyseal Nonunions. J Orthop Trauma 1997; 11(7): 513-520.

13. Green SA. Skeletal defects. A comparison of bone grafting and bone transport for segmental skeletal defects. Clin Orthop Relat Res 194;(301):111-117.

14. Ilizarov GA. Clinical application of the tension-stress effect for limb lengthening. Clin Orthop Relat Res 990 (250): 8-26.

15. Cypher TJ \& Grossman JP. Biological principles of bone graft healing.J Foot Ankle Surg 1996; 35(5): 413-417.

16. Langer $R$ \& Vacanti JP. Tissue engineering. Science 1993; 260(5110): 920-926.

17. Kon E, Muraglia A, Corsi A, Bianco P, Marcacci M, Martin I \& et al. Autologous bone marrow stromal cells loaded onto porous hydroxyapatite ceramic accelerate bone repair in critical-size defects of sheep long bones. J Biomed Mater Res 2000; 49(3): 328-337.

18. Albrektsson $T$ \& Johansson C. Osteoinduction, osteoconduction and osseointegration. Eur Spine $J$ 2001; 10(2): S96-S101.

19. Cornell CN \& Lane JM. Current Understanding of Osteoconduction in Bone Regeneration. Clin Orthop Relat Res 1998; 355: S267-S273.

20. Nouri A, Hodgson PD \& Wen C. Biomimetic Porous Titanium Scaffolds for Orthopedic and Dental Applications Rijek, Croatia: InTech; 2010.

21. Bauer TW, \& Muschler GF. Bone Graft Materials: An Overview of the Basic Science. Clin Orthop Relat Res 2000; 371: 10-27.

22. Gazdag AR, Lane JM, Glaser D \& Forster RA. Alternatives to Autogenous Bone Graft: Efficacy and Indications. J Am Acad Orthop Surg 1995; 3(1): 1-8.

23. Cook SD, Thomas KA, Kay JF \& Jarcho $M$. Hydroxyapatite-coated titanium for orthopedic implant applications. Clin Orthop Relat es 988; (232): 225-243.

24. D'Antonio JA, Capello WN, Manley MT \& Feinberg J. Hydroxyapatite coated implants. Total hip arthroplasty in the young patient and patients with avascular necrosis. Clin Orthop Relat Res 1997;(344): 124-138.

25. Miron RJ \& Zhang YF. Osteoinduction: A Review of Old Concepts with New Standards. J Dent Res 2012; 91(8): 736-744.

26. Al-Aql ZS, Alagl AS, Graves DT, Gerstenfeld LC \& Einhorn TA. Molecular Mechanisms Controlling Bone Formation during Fracture Healing and Distraction Osteogenesis. J Dent Res 2008; 87(2): 107-118.

27. Tsiridis E, Bhalla A, Ali Z, Gurav N, Heliotis M, Deb $S$, et al. Enhancing the osteoinductive properties of hydroxyapatite by the addition of human mesenchymal stem cells, and recombinant human osteogenic protein-1 (BMP-7) in vivo. Injury 2006; 37(3, Supplement): S25-S32.

28. Livingston $T L$, Gordon $S$, Archambault $M$, Kadiyala S, Mclntosh K, Smith A, et al. Mesenchymal stem cells combined with biphasic calcium phosphate 
ceramics promote bone regeneration $2003 \mathrm{~J}$ Mater Sci Mater Med; 14(3): 211-218.

29. Aoki H. Medical application of hydroxyapatite. Euro America Inc 1994.

30. Bucholz RW, Carlton A \& Holmes RE. Hydroxyapatite and tricalcium phosphate bone graft substitutes. Orthop clinNorth Am 1987; 18(2): 323-334.

31. Holmes RE, Bucholz RW \& Mooney V. Porous hydroxyapatite as a bone graft substitute in diaphyseal defects: A histometric study. J Orthop Res 1987; 5(1): 114-121.

32. Uchida A, Nade SM, McCartney ER \& Ching W. The use of ceramics for bone replacement. A comparative study of three different porous ceramics. J Bone Joint Sur Br 1984; 66(2): 269-275.

33. Hench LL, Splinter RJ, Allen WC \& Greenlee TK. Bonding mechanisms at the interface of ceramic prosthetic materials. J Biomedic Mater Res 1971; 5(6): 117-141.

34. Maria V-R. Ceramics for medical applications. J Chem Soc, Dalton Trans 2001; (2): 97-108.

35. De Groot K. Bioceramics of Calcium Phosphate J Cinic Eng (1984); 9(1): 52.

36. Yoshikawa H, Tamai N, Murase T, \& Myoui A. Interconnected porous hydroxyapatite ceramics for bone tissue engineering. J R Soc Interface 2009; 6(Suppl 3): S341-S348.

37. Babis GC \& Soucacos PN. Bone scaffolds: The role of mechanical stability and instrumentation. Injury 2005; 36(Suppl): S38 - S44.

38. Mahan KT \& Carey MJ. Hydroxyapatite as a bone substitute. J Am Podiatr Med Assoc 1999; 89(8): 392397.

39. Kalfas IH. Principles of bone healing. Neurosurg Focus 2001; 10(4): E1.

40. Arita IH \& Castano VM \& Wilkinson DS. Synthesis and processing of hydroxyapatite ceramic tapes with controlled porosity. J Mater Sci Mater Med 1995; 6(1): 19-23.

41. Tancred DC, McCormack BA \& Carr AJ. A synthetic bone implant macroscopically identical to cancellous boe. Bomaterials (1998); 19(24): 2303-2311.

42. White RA, Weber JN \& White EW. Replamineform: a new process for preparing porous ceramic, metal, and polymer prosthetic materials. Science 1972; 176(4037): 922-924.
43. Ramay HR \& Zhang M. Preparation of porous hydroxyapatite scaffolds by combination of the gelcasting and polymer sponge methods. Biomaterials 2003; 24(19): 3293-3302.

44. Damien CJ, \& Parsons JR. Bone graft and bone graft substitutes: A review of current technology and applications. J App/ Biomater 1991; 2(3): 187-208.

45. Ray DM., W., Eysel, \& White E, W. (1974). Hydrothermal synthesis of various carbon containing calcium hydroxyptite. Matter Re. Bull 1974; 9: 35.

46. Cuneyt Tas A, Korkusuz F, Timucin M \& Akkas N. An investigation of the chemical synthesis and high-temperature sintering behaviour of calcium hydroxyapatite (HA) and tricalcium phosphate (TCP) bioceramics. J Mater Sci Mater Med 1997; 8(2): 9196.

47. Bouyer E, Gitzhofer F \& Boulos MI. Morphological study of hydroxyapatite nanocrystal suspension. J Mater Sci Mater Med 2000; 11(8): 523-531.

48. Liu DM, Yang Q, Troczynski T \& Tseng WJ. Structural evolution of sol-gel-derived hydroxyapatite. Biomaterials 2002; 23(7): 1679-1687.

49. Oonishi H, Hench LL, Wilson J, Sugihara F, Tsuji E, Kushitani S, et al. Comparative bone growth behavior in granules of bioceramic materials of various sizes. J Biomed Mater Res 1999: 44(1); 31-43.

50. Fathi MH \& Hanifi A. Evaluation and characterisation of nanostructure hydroxyapatite powder prepared by simple sol-gel method. Mater Lett 2007; 61(18): 3978-3983.

51. Bruder SP, Fink DJ \& Caplan Al. Mesenchymal stem cells in bone development, bone repair, and skeletal regenaration therapy. J Cell Biochem 1994; 56(3): 283-294.

52. Woodard JR, Hilldore AJ, Lan SK, Park CJ, Morgan AW, Eurell JA, et al. The mechanical properties and osteoconductivity of hydroxyapatite bone scaffolds with multi-scale porosity. Biomaterials 2007: 28(1): 45-54.

53. Hench LL \& Ethridge EC. Biomaterials:An Interfacial approach. Academic Press, New York 1982.

54. Quarto R, Mastrogiacomo M, Cancedda R, Kutepov S, Mukhachev V, Lavroukov A, et al. Repair of Large Bone Defects with the Use of Autologous Bone Marrow Stromal Cells. N Engl J Med 2001; 344(5): 385-386. 